\title{
EFFECT OF HYALURONIDASE ON THE VISCOSITY OF THE AQUEOUS HUMOUR*
}

\author{
BY
}

\section{J. A. BESWICK AND CLEMENT MCCULLOCH}

Department of Ophthalmology, University of Toronto, Ontario

BÁRÁNY and Scotchbrook (1954) described a hyaluronidase-sensitive barrier to aqueous outflow in the angle of the anterior chamber of enucleated cattle eyes. Their conclusions were based upon the observation that the addition of hyaluronidase to the perfusing fluid increased the rate of outflow.

Hyaluronic acid was demonstrated in bovine aqueous by Meyer and Palmer (1936). Hyaluronidase has a specific action (Meyer, 1947), reducing the viscosity of hyaluronic acid by a mechanism which is thought to consist of depolymerization followed by hydrolysis. Could hyaluronic acid in the aqueous, rather than in the angle, of the eyes used by Bárány have been the substrate? Although the anterior chambers were washed out before the readings were taken, residual hyaluronate could have produced the observed results. Finally, it is possible that a solution of hyaluronidase may have had a detergent action, altering the rate of flow through the angle.

This experiment was planned to demonstrate the effect of both hyaluronidase, and of a wetting agent, on the rate of flow of aqueous humour, under controlled conditions. These effects were noted in terms of change in viscosity. Viscosity is described (Seifriz, 1944) as the "reciprocal of fluidity". Under controlled conditions, the rate of flow of a liquid is inversely proportional to its viscosity.

\section{Method}

An Ostwald viscosimeter pipette was used. A constant volume of liquid was allowed to flow by gravity through a small-bore glass tube. The length of time required for the liquid to flow is a relative measure of its viscosity. The relative viscosity of a liquid is the ratio of its flow-time to that of distilled water.

A water-bath maintained temperatures within a range of $37^{\circ}-37.5^{\circ} \mathrm{C}$.; preliminary observations showed that variations of $0.5^{\circ} \mathrm{C}$. did not affect the result.

Viscosity measurements were made of pooled aqueous, and of various other liquids, namely, distilled water, normal saline, egg albumen solution, human serum, and vitreous solution. Hyaluronidase was added to each of these, and, in separate experiments, a detergent solution was added to most of them.

The hyaluronidase preparation (Wydase, 450 V.R.U./ml.) $\dagger$ was added to the liquid already in the pipette and mixing was carried out there, by about ten inversions of the instrument. The wetting agent, a concentrated solution of Alconox, was added in the same way, $0 \cdot 1 \mathrm{ml}$. of each additive being used in separate experiments. This gave a concentration of approximately ten V.R.U. hyaluronidase

* Received for publication April 20, 1956.

† John Wyeth and Brother (Canada) Ltd.

11

545

$\ddagger$ Alconox Inc. 
per $\mathrm{ml}$. to those solutions so treated. The detergent solution was judged sufficiently potent by the fact that,it imparted a soapy feel to those liquids to which it was added. Trial experiments demonstrated that the addition of $0.1 \mathrm{ml}$. fluid to the system did not, per se, alter the result.

It was soon evident that fresh aqueous behaved differently from aqueous taken from stored eyes. Consequently, the following experiment was devised:

Cattle eyes were collected at the abattoir one hour post mortem, and were divided into $\frac{\mathbb{Q}}{\mathbb{Q}}$ two lots:

Lot 1.-The aqueous was withdrawn by a syringe fitted to a 21 needle, the puncture being $\vec{\circ}$ made about $2 \mathrm{~mm}$. anterior to the limbus. Half the material so obtained was stored at $40^{\circ} \mathrm{F}$. Determinations of viscosity were made immediately on the fresh $\vec{\omega}$ half, and 7 days later on the refrigerated portion.

Lot 2.-The intact eyes were refrigerated at $40^{\circ} \mathrm{F}$. for 7 days. The aqueous was then with- $\frac{0}{0}$. drawn and the viscosity measured.

All figures shown in the Tables are an average of five consecutive readings. These $i f$ all lay within a range of \pm 1 per cent. except for vitreous solution and for aqueous from $\frac{1}{\sim}$ stored eyes, both treated with hyaluronidase. In the case of the two last, consecutive 0 readings during a 10-minute period showed a decreasing viscosity.

\section{Results}

Table I records the effect of additives to the fluids other than aqueous $\frac{\mathbb{D}}{3}$ humour. The only significant change in viscosity followed the addition of $\stackrel{\oplus}{-}$ hyaluronidase to the solution of vitreous humour (half vitreous and haff $\overrightarrow{0}$ distilled water). The detergent had no viscosity-reducing effect.

TABLE I

RELATIVE VISCOSITIES OF VARIOUS SOLUTIONS USED AS CONTROLS

\begin{tabular}{|c|c|c|c|c|c|}
\hline \multirow{2}{*}{\multicolumn{2}{|c|}{$\begin{array}{l}\text { Control } \\
\text { Materials }\end{array}$}} & \multicolumn{3}{|c|}{ Relative Viscosity } & \multirow{2}{*}{$\begin{array}{c}\text { Per cent. } \\
\text { Change } \\
\text { in } \\
\text { Viscosity }\end{array}$} \\
\hline & & $\begin{array}{c}\text { No } \\
\text { Additive }\end{array}$ & $\stackrel{+}{\text { Hyaluronidase }}$ & $\stackrel{+}{+}$ & \\
\hline $\begin{array}{l}\text { Distilled water ... } \\
\text { Normal saline } \ldots \\
\text { Egg albumen solution } \\
\text { Human serum ... } \\
\text { Vitreous solution }\end{array}$ & $\begin{array}{ll}\cdots & \cdots \\
\cdots & \cdots \\
\cdots & \cdots \\
\cdots & \cdots \\
\cdots & \cdots\end{array}$ & $\begin{array}{l}1.00 \\
1.02 \\
1.22 \\
1.58 \\
1.29\end{array}$ & $\begin{array}{l}0.99 \\
1.02 \\
1 \cdot 22 \\
1 \cdot 57 \\
1.07\end{array}$ & $\begin{array}{l}1.00 \\
1.02 \\
1 \cdot 22 \\
1 \cdot 58 \\
1 \cdot 29\end{array}$ & $\begin{array}{r}-1 \\
0 \\
0 \\
-1 \\
-17\end{array}$ \\
\hline
\end{tabular}

Table II (opposite) shows the effect of the same two additives on the viscosity of bovine aqueous in various states of preservation, and on fresh rabbit and pooled human aqueous. The human aqueous was taken from $\tilde{N}$ otherwise normal eyes at the time of cataract extraction.

These results show that the detergent again had no effect. However, the viscosity of aqueous increased post mortem when stored in oculo, and this increase was significantly reduced by hyaluronidase. Storage in vitro did not alter the viscosity of aqueous. 
TABLE II

RELATIVE VISCOSITIES OF VARIOUS SOLUTIONS OF AQUEOUS HUMOUR

\begin{tabular}{|c|c|c|c|c|c|c|c|c|}
\hline \multirow{2}{*}{\multicolumn{5}{|c|}{ Aqueous }} & \multicolumn{3}{|c|}{ Relative Viscosity } & \multirow{2}{*}{$\begin{array}{c}\text { Per cent. } \\
\text { Change } \\
\text { in } \\
\text { Viscosity }\end{array}$} \\
\hline & & & & & \multirow{2}{*}{$\begin{array}{c}\begin{array}{c}\text { No } \\
\text { Additive }\end{array} \\
1.03 \\
1.05 \\
1.28 \\
1.00 \\
1.03\end{array}$} & \multirow{2}{*}{$\begin{array}{c}\stackrel{+}{+} \text { Hyaluronidase } \\
1.03 \\
1.05 \\
1.12 \\
1.01 \\
1.02\end{array}$} & $\begin{array}{c}+ \\
\text { Detergent }\end{array}$ & \\
\hline $\begin{array}{l}\text { Bovine f } \\
\text { Bovine } r \\
\text { Bovine } r \\
\text { Human } \\
\text { Rabbit }\end{array}$ & $\begin{array}{r}e r a \\
\ldots \\
\ldots\end{array}$ & $\begin{array}{l}\text { in } \\
\text { in } \\
\ldots \\
\ldots\end{array}$ & & $\begin{array}{l}\cdots \\
\cdots \\
\cdots \\
\cdots \\
\cdots\end{array}$ & & & $\begin{array}{c}1.03 \\
1.05 \\
1.28 \\
- \\
-\end{array}$ & $\begin{array}{r}0 \\
0 \\
-12 \\
+1 \\
-1\end{array}$ \\
\hline
\end{tabular}

\section{Discussion}

Because of the specificity of hyaluronidase, the marked decrease in viscosity of a solution of vitreous when treated with hyaluronidase (Table I) can be assumed to be due to the presence of polymerized hyaluronate in the solution. Similarly, a significant part of the increase in viscosity of aqueous stored in oculo (Table II) and the decrease in viscosity when the aqueous is treated with hyaluronidase may be assumed to be due to the presence of polymerized hyaluronate. Testing of fresh aqueous did not indicate the presence of polymerized hyaluronate. This is in keeping with the statement of Meyer (1947) that the hyaluronic acid normally present in aqueous humour is 95 per cent. depolymerized. Thųs it seems that Bárány's observations were not due to substrate in the aqueous of the fresh, undisturbed eyes. Nor is it likely that the hyaluronidase Bárány used was acting as a wetting agent (Table II).

Our finding of a post-mortem increase in polymerized hyaluronate in the aqueous humour may have been due to movement of the polysaccharide forward from the vitreous, as a simple diffusion or following post-mortem degeneration of the vitreous. An alternative explanation could be that in the living eye the relationship between hyaluronate and hyaluronidase is such that the hyaluronic acid is largely depolymerized, while after death the balance shifts, resulting in an increase in polymerized hyaluronate in the aqueous.

If polymerized hyaluronate were present in the aqueous of the eyes used by Bárány, it could have entered by post-mortem diffusion from the vitreous, increased by handling the eyes, or could have appeared as a post-mortem change in the balance between hyaluronate and hyaluronidase in the anterior chamber.

The possibility of post-mortem change was considered by Bárány and Scotchbrook (1954) in their original report. Using eyes incubated at $37^{\circ} \mathrm{C}$. for periods up to $5 \frac{1}{2}$ hours the experiment was repeated. The incubated eyes behaved in the same manner as the fresh ones. During the $5 \frac{1}{2}$-hour period of observation a diffusion of polymerized hyaluronate from the 
vitreous was not taking place, or the balance between hyaluronate and hyaluronidase in the aqueous was not changing. Our observation that polymerized hyaluronate appears in the aqueous after a week's storage in oculo tends to confirm Bárány and Scotchbrook's findings and to suggest $\stackrel{\vec{D}}{\vec{D}}$ that there is no significant change in the polysaccharide during a $5 \frac{1}{2}$-hour period.

For fresh eyes, as used by Bárány, mechanical handling is not a factor in $\vec{\Phi}$ increasing the content of polymerized hyaluronate in the aqueous. This point was clarified by the following experiment:

A series of fresh cattle eyes was manually rolled on a hard surface for 10 minutes under a pressure of approximately $7 \mathrm{lb}$. This was thought to exceed the degree of $\vec{\omega}$ trauma in Bárány's experiment, but it did not produce any significant change in viscosity of the aqueous.

The work reported here tends to support the theory set forward by $\vec{i}$ Bárány to explain his observations. Our experiments indicate that changes ir in quantity of polymerized hyaluronate in the aqueous cannot explain 0 Bárány's findings. Therefore it is possible that polymerized hyaluronate is 9 a part of the tissue of the angle, or that a "clot" of polymerized poly- $\vec{c}$ saccharide from the aqueous may be deposited in the drainage channels.

However, the post-mortem rise in the content of polymerized hyaluronate $\stackrel{\oplus}{\rightrightarrows}$ in the aqueous reported here indicates that there may still be a relation $\stackrel{\Phi}{\sim}$ between polymerized hyaluronate in the aqueous and certain pathological $\vec{\varphi}$ conditions, particularly glaucoma. A link between the viscosity of aqueous $\mathrm{O}$ and the aetiology of glaucoma was suggested by Meyer and Palmer (193) when they first discovered and named hyaluronic acid. Later Meyer, Smyth, and Gallardo (1938) reported an investigation of this point, in which they determined chemically the hyaluronic acid content of the aqueous of $\frac{\mathscr{D}}{\mathbb{D}}$ normal and glaucomatous human eyes. Their method did not take into $\stackrel{\circ}{\Rightarrow}$ consideration the degree of polymerization of the acid and the results were inconclusive. It is possible that the balance between polymerized and depolymerized hyaluronic acid in the tissues and fluids of the eye varies during life, and that this variation is a factor in the aetiology of chronic $\frac{0}{0}$ simple glaucoma.

\section{REFERENCES}

BáráNY, E. H., and SCOTCHBroOK, S. (1954). Acta physiol. scand., 30, 240.

MeYer, K. (1947). Physiol. Rev., 27, 335. and Palmer, J. W. (1934). J. biol. Chem., 107, 629.

(1936). Amer. J. Ophthal., 19, 859.

SMYTH, E., and GaLlardo, E. (1938), Ibid., 21, 1083.

SEIFRIZ W. (1944). In "Medical Physics", ed. O. Glasser, Chicago. 